\title{
On Palimpsests: How to Use this Concept for Translation Studies. In Memoriam Gérard Genette (1930-2018)
}

\author{
By Hans-Harry Drößiger*
}

\begin{abstract}
This article was written in memoriam Gérard Genette who died on May 11, 2018. The purpose of this article is to honor the work Palimpsests by this famous French scholar and researcher into literature. He has shown manifold ways to deal with different methods of creating a text considering the fact that to almost every text in the history of mankind at least one text preexists. By explaining a huge number of instances how from an older text a newer one can be created, Genette was able to present a systematic approach to all these changes covered by the concept of palimpsest or palimpsestic processes of creating a hypertext from a hypotext. On this concept grounds the basic idea of this article to seek for ways to make the concept of palimpsest applicable to translation studies. This is especially due to the fact that for almost two decades now scholars in translation studies have been complaining about the horribly immense number of terms that are in use amongst the scholars and that almost no consensus in terminology exists or was about to come into life. The positions outlined in this article are about to see beyond one's nose because it shall be taken for granted that in neighboring research areas and scholarly occupations some well reasoned notions were developed, which are worth to be studied.
\end{abstract}

Keywords: Gérard Genette, Palimpsest, Translation, Translation studies

\section{Introduction}

On May 11, 2018, the famous French scholar in literary research and philosopher Gérard Genette died. This article wishes to honor his groundbreaking work on palimpsests, which still may open new avenues of research not only into literature and its history but also into language, language use, translation and perhaps many more areas surrounding these fields. In this article, I want to present Genette's concept of palimpsests, which is thoroughly described in his monograph Palimpsests, and how to make these ideas applicable for translation studies.

The first hint to recall the idea of palimpsests came during the studies of Pérez-González's book Audiovisual Translation Studies where this Spanish scholar stated that audiovisual translations are best conceptualized as "palimpsestic" forms of mediation (2014: 165). However, not only results of audiovisual translations can be characterized in this way, classic forms of translation can be as well. This leads to the question what palimpsests are and how to make the concept of palimpsests applicable for translation studies. For this reason, the book Palimpsests by Gérard Genette in its English translation from 1997, which I will refer to (French original 1982), has to be considered because Genette presents a wide overview to any possible form of transdoing or redoing a given text or a given story to be told, including translations amongst other well known ways of culturally related presentations of literary and other narrative material. Roland Barthes, another leading figure of literary research and a contemporary of Genette, described narrative as follows:

\footnotetext{
${ }^{*}$ Full Professor \& Senior Researcher, The Kaunas Faculty, Vilnius University, Lithuania.
} 
... there can be no doubt that narrative is a hierarchy of instances. To understand a narrative is not merely to follow the unfolding of the story, it is also to recognize its construction in "stories", to project the horizontal concatenations of the narrative "thread" onto an implicitly vertical axis; to read (to listen to) a narrative is not merely to move from one word to the next, it is also to move from one level to the next ... It is proposed to distinguish three levels of description in the narrative work: the level of "functions" ..., the level of "actions" ... and the level of "narration" ... . (Barthes 2000: 259-260)

Considering this idea, a writer, a poet and a translator as well might act in this manner creating their work by transdoing and/or redoing. Although the whole area of palimpsestic forms of transdoing or redoing looks quite manifold, difficult and complex, it may be summarized under the headline Ways how to tell a good story. The emphasis in this summarizing statement is on "a good story" and shall not be confused with Ways to tell a story well because these "good stories" constitute uniqueness in literature and the ways good stories might be told. However, after having studied Palimpsests, I assume that no one can tell an exact number of "good stories" or state when for the first time in the history of mankind a good story was told. This leads to the conclusion that any literary story once stored in a written form and belonging nowadays to our literary heritage might be a palimpsestic one. Grounding on this idea, methods, techniques of telling a story are to represent some sort of a former story.

Despite of the outstanding value of Genette's book, it can be taken as a starting point for a completely legal enterprise, reading and interpreting the content of it against the background of scientific interests or research endeavors. This is especially due to the fact that for about four decades scholars in translation studies have been complaining about the horribly immense number of terms that are in use amongst the scholars and that almost no consensus in terminology exists or was about to come into life (cf. Holmes 1975: 68, Díaz Cintas 2004: 31, SnellHornby 2006: 27). In the following, I will use opinions, statements, outlines Genette has done in his book to work out some problems or to open up new facets related to translation studies, esp. to audiovisual translation studies (AVTS). However, although Genette wrote his book several decades ago, it could be a real treasure chest for a scholar who is willing to see interrelations between Genette's ideas on palimpsests and that what a huge number of translation scholars call "translation". Also, I take it for granted that a scholar should lay claim on taking a look beyond the boundaries of their original field of research and studies, especially in the humanities, to improve their view to the world.

Making use of the monograph by Genette, I will compile a system of necessary terms he used to present the idea of palimpsests and how these terms are also suitable to be applied in translation studies. Conducting this, I will also name problems/issues, which I interpreted reading Palimpsests to make clear what I take for important to do a part in our discussions about translation studies, although Genette had this only indirectly in mind.

It is not the aim of this article to discuss influences on Genette, esp. by his contemporaries, like Barthes, Kristeva, to name a few, or how Genette's work influenced these amongst many others considering theories of narration, 
mythology, literature, and translation. Only some brief references to such figures and their works shall be mentioned. Generally, the emphasis is set on Genette's work Palimpsests.

\section{The Concept of Palimpsest by Gérard Genette}

Although Genette gave his book the title Palimpsests, he did not directly define this term as such. Instead of this and according to the basic idea of palimpsests, the term hypertextuality was introduced to set foundations for the whole investigation into palimpsests. In this sense, Genette presented a kind of provisional definition:

By hypertextuality I mean any relationship uniting a text B (which I shall call the hypertext) to an earlier text A (I shall, of course, call it the hypotext), upon which it is grafted in a manner that is not that of a commentary. The use of the metaphoric "graftet" and of the negative determination underscores the provisional status of this definition. To view things differently, let us posit the general notion of a text in a second degree ...: i.e., a text derived from another preexistent text. (1997: 5)

This concept of palimpsest can be made fit for any form of translation in theory and practice, although Genette in his monograph for himself did not work much on problems of translation. Nevertheless, creating one short formula, we may say that:

\section{palimpsest $=$ transdoing from hypotext to hypertext by perspectivation}

The subject-related terms are "hypotext" and "hypertext", the process-related terms are any kind of "transdoing" and "perspectivation", whereas the latter may include a translator's very personal, subjective attitude or conception on how to perform a certain translation. Genette defined hypertext as follows:

What I call hypertext ... is any text derived from a previous text either through simple transformation, which I shall simply call from now on transformation, or through indirect transformation, which I shall label imitation. (1997: 7)

Going forward, Genette also presented abstractions from the subject-related pair of terms, hypotext-hypertext, up to an abstract, summarizing or generalizing term, hypertextuality, which covers all instances a hypotext (the basic or original, the primary text) was somehow transformed into a hypertext (the derived, transformed, the secondary text), which comes in a chronological order later than the hypotext. ${ }^{1}$

\footnotetext{
${ }^{1}$ Comparing Genette's hypotext-hypertext relation as a chronological and logical one with ideas like "intertextuality", e.g. by Kristeva, would not come - from my point of view- to this essential point of orderly comprehension since the term "intertextuality" implies some sort of equality between the involved texts or narratives.
} 
Although Genette did not emphasize audiovisual media and the processes between traditional media and the more modern ones, it is interesting to see that he included some single facts from or experiences with audiovisual media. Doing so, Genette coined some valuable terms to name his observations in audiovisual media, here, for example, as cinematographic hypertextuality:

The title of Woody Allen's film Play It Again, Sam (1972) acts for film connoisseurs as a contract of cinematographic hypertextuality (hyperfilmicity). They recognize it as the most famous ... line from the Michel Curtiz film Casablanca ... . (1997: 156)

This special form of hypertextuality (in films, between films) should be subject to further investigation, esp. in the sense of re-making films, to find out not only relations between an original film and its re-created versions using allusions (quotes, titles, characters from the original film) but also in the sense of real remakes. For translation studies the most challenging question in this case might be, how an original film and its re-make have an impact on the translation of the remade version. What kinds of, for instance, intersemiotic relations or changes between the versions of a film can be stated, which might bias a film translation?

\section{Transdoing}

The generic term transdoing I used here in this formula covers all the transterms we may find in the specialized literature on translation, from transfer to translation to transadaptation, etc. What makes a transdoing a palimpsestic one is its combination with an altered or changed perspective, which differs from the original one. Amongst the trans-terms, Genette used in his work, we find "transformation", "transposition", "transmodalization", "transstylization", and "translation". Logic dictates that a number of these terms refer to the general process of transdoing, like transformation, transposition, translation, while others refer to single methods/techniques, which can be applied conducting the transdoing, as there are transmodalization and transstylization. The reason for using this pair of terms - methods and techniques - grounds in the logical and scientific distinction between the two complementary concepts of PROCESS and RESULT, which shall be taken as the theoretical and methodological basis for terms in use to describe instances of translation (cf. Molina \& Albir 2002: 506-507). Later on, I will consequently use this pair of terms to emphasize that a researcher may have both the process and the result of a translation in mind.

Amongst all the trans-terms, especially transformation seems to be not only the most essential, but also the most shifting concept. Therefore, Genette introduced some specifications to transformation, e.g., semantic transformation, but his notion of "semantic" is quite different from the notion in linguistics. He has a thematic change in mind:

The dominant effect that concerns me now is ... a thematic transformation bearing on the very significance of the hypotext; to a transformation of that type I shall assign the term semantic, which speaks for itself. (1997: 294) 
Another specification of transformation, closely related to semantic transformation, are so-called pragmatic transformations:

We shall encounter many more pragmatic transformations; those, however, will be constantly subsumed within semantic transformations from which they cannot be dissociated, or even distinguished. (1997: 317)

While semantic and pragmatic transformations are related to the ways a process of transforming will go on, Genette also presents textual transformation, which is obviously more closely related to the subject that has to undergo this process. As such a subject-related term, it may include or refer to subsequent procedures how a textual transformation might be performed.

Reduction and amplification are not as separate as would appear from the two distinct examples discussed above. First, as has already been seen, textual transformations that cannot fall easily into either of those two categories generally result from their combination, according to the formula addition + suppression $=$ substitution $\ldots$. (1997: 269 - bold typeface: author)

Later on in this paper, I will return to these more specific methods or techniques of transformation, namely addition, suppression and substitution, which are indeed well known among scholars and practitioners of translation studies.

Since Genette uses the term transposition also as a major term, as one of the most common terms or simply as a term that may cover processes and forms of trans- or redoing of a hypotext to create a hypertext, he looks for all possible ways to do so. Having especially films in mind, Genette brings a certain form of transposition into play:

One could imagine a transposition that would be content with aging the protagonists (Daphnis and Chloe in their fifties) or with rejuvenating them (Philemon and Baucis as adolescents) without modifying the pattern of their behavior ... Only film, bound as it is on the aging of its actors, seems in a position to explore that formula: e.g., in High Noon, Rio Bravo, El Dorado. But there, identity of action is generic rather than singulative ... . (1997: 297-8)

Many modern forms of cinematography use this "making the main characters older or younger". This happened in the Harry Potter franchise as well as in other films with flashbacks into the past or in Sci-fi films telling stories of time travelling.

Only as a footnote, yet no less important is Genette's statement about the term practice as part of the concept of transposition: "Practice seems to me here to be the handiest and most appropriate term to designate what is, after all, a type of operation" (1997: 433, footnote 4 to chapter 7). On another position, Genette uses the term practice in relation to a framework of translation. For this reason, he distinguishes two basic forms:

... transpositions that are in principle (and in intention) purely formal, which affect meaning only by accident or by a perverse and unintended consequence, as 
in the self-evident case of translation (which is a linguistic transposition); and transpositions that are overtly and deliberately thematic, in which transformation of meaning is manifestly, indeed officially, part of the purpose ... . (1997: 214)

Interestingly, here Genette introduces a description of the term translation as a "linguistic transposition" in a formal way, which has or should not have any impact on content, sense, meaning or any other semiotic characteristics of an original text.

Although very briefly, Genette names the term and some basic problems of translation on different positions in his Palimpsests. In most cases, translation appears in a row with other, similarly understood phenomena.

... that there is no such thing as an innocent transposition: i.e., one that does not in one way or another alter the meaning of its hypotext. True enough, the semantic alterations entailed by translation, versification, and most of the "formal" transpositions we have just been discussing generally result from unintended distortions inherent in those procedures, rather than from any deliberate purpose. The sole aim of a translator ... is to say "the same thing" as the hypotext in another language, in verse, or in more compact form; such transpositions are thus in principle purely formal. (1997: 294)

In a similar way, Genette tells that there is no innocent transformation, in which there is no way to modify the words without altering the meaning of them (1997: 317). The term translation, or in other words, the phenomenon of translation is not one of Genette's special topics, but on several positions in his book, he mentions translation as one of the procedures of how to transform a hypotext into a hypertext. Generally, Genette seems to share a statement about translation by R. Barthes, "narrative, in other words, is translateable without fundamental damage ... The translatability of narrative is a result of the structure of its language ..." (Barthes 2000: 292). Thus, the following quotes present some pieces of notion of translation.

... and if one integrates the (small) constant coefficient of mechanical expansion entailed by the switch from Latin to French, the approximate ratio of the increase is 2 to $1 .(1997: 61)^{2}$

Some theoretical statements about translation and its research and academic presentation are done by Genette:

The most visible form of transposition, and certainly the most widespread, consists in transposing a text from one language to another. This is, of course, translation ... This is not the place to go into the familiar "theoretical"- or other-problems of translation; there are good books and bad books on that subject, and everything in between. (1997: 214)

\footnotetext{
${ }^{2}$ A similar observation can be made translating into German, which appears as a quite analytical language with the effect of using longer, more extensive syntactic constructions than are usual in a synthetical language.
} 
He continues his ideas as follows:

... the most appropriate formula is perhaps that of the linguist E.A. Nida, who goes to the heart of things without distinguishing between prose and poetry: "Anything that can be said in one language can be said in another, unless the form is an essential element of the message". (1997: 215)

Another interesting snippet to understand translation is the following, in which Genette, without using certain categories, says:

The explorer's illusion, and therefore the translator's temptation, is to take these clichés literally and to render them in the translated version by figures that are not in common use. (1997: 216)

This difference between linguistic and other aspects between several languages leads to that what another scholar has described as linguistic and social inappropriateness (Fernández 2009: 211-212) when doing translations.

Interestingly, Genette not only has actual processes of translation in mind but also the historical dimension of translation:

To these, as it were, horizontal (synchronic) difficulties raised by the passage from one language to another, we must add, in the case of ancient works, a vertical or diachronic difficulty that has to do with the evolution of languages. (1997: 217)

Genette had not the intention to continuously talk about translation and related problems. However, his outlines about specific palimpsestic methods/techniques partially fit to translation. One of these methods/techniques is called reduction.

But here ... the imitation seeks only (and is only able) to retain translinguistic elements: that is, elements that are independent of the original language (Greek or Latin) and are susceptible to transposition into another language. The Homeric dialectal traits, for example, have no equivalent in Boileau's work, nor does the dactylic hexameter. Hence the "epic style" is reduced to a certain number of canonic "figures" and thematic motifs. (1997: 135)

His specifications of palimpsestic methods/techniques amongst transformational practices were captured with some special terms, e.g., transmodalization:

Our last type of purely formal transposition ... will be transmodalization: i.e., any kind of alteration in the mode of presentation characterizing the hypotext. At issue, then, is a change of mode, or a change within the mode, but not a change of genre ... . (1997: 277)

I designate as transmodalization, less ambitiously, a transformation bearing on what has been termed, since Plato and Aristotle, the mode of presentation of a work of fiction, which can be narrative or dramatic. Modal transformation can, on the face of it, be one of two sorts: intermodal (involving a shift from one mode to another) or intramodal (involving changes within the internal functioning of the mode). This 
twofold distinction affords us four variations. Two are intermodal: the shift from the narrative to the dramatic, or dramatization, and the reverse shift from the dramatic to the narrative, or narrativization. And two are intramodal: variations within the narrative mode and within the dramatic mode. (1997: 277-8)

Very briefly, Genette mentioned the method/technique of transstylization as a change of the style by narrating or telling a story (cf. 1997: 124).

To close up this overview to Genette's trans-terms, one of their possible results might be thematized, intersemiotic relations. Since intersemiotic aspects have been taken as important for audiovisual translation studies, there should be appropriate descriptions given about that what is called intersemiotics/ intersemiotic relations. Genette in his book Palimpsests introduces ideas on intersemiotics without looking at films or any other audiovisual material or even the mass media. However, ideas of intersemiotics are explicitly told in chapter 79 (1997: 384-394) concerning literature, music (esp. classical music), painting and other forms of plastic arts. Genette's approach to intersemiotics starts on a very high level of comprehension, and, he focuses on non-interchangeable things appearing in several semiotic fields. For this observation, Genette uses the common term "hyperaesthetic practices", which can be interpreted as semiotics.

The materials and techniques that are open to transformation and imitation are not the same; there are differences, sometimes of a fundamental nature, in the modes of existence and reception, in the ontological status of the works (consider, for example, the capital part played in musical discourse by repetition, for which there is no equivalent in painting, and almost none in literature ...; or consider the simple fact that literature is the only art that partakes of, or benefits from, the plurality of languages), and meaning comes about differently too. There is nothing in music that corresponds to the semantic transformations of the type found in Tournier's Friday, nothing in literature that corresponds to so elementary and efficient an operation as a simple melodic line's shift from a major to a minor key. (1997: 391-2)

\section{Perspectivation}

Perspectivation, as a term introduced by Graumann and Kallmeyer (2002), is about to give the more widely used term perspective a complement to emphasize the relation between process - the perspectivation - and its result - the perspective - and as a common cognitive and communicative practice as well. As Graumann and Kallmeyer suggest, both perspective and perspectivation are founding instances of any discourse.

The study of perspectivation poses questions with respect to the role that communication of perspectives plays in text and interaction, and what important strategies of perspectivation one can observe in different contexts. For the analysis of human strategies of orientation in space and time spatial reference ... proved to be of primordial interest (Weissenborn and Klein 1982). From here it is only a short step to the analysis of referential movements in texts (Klein and Stutterheim 1989) and its interpretation as representation of perspectival moves (Graumann and Kallmeyer 2002: 5). 
Considering this, perspectivation can be taken as a form of conceptual movements within the mental space of contiguity, in short terms: a metonymical movement. Genette has developed his own approach to perspective, which refers to sorts of text or, so to speak, to genres of literary texts. The words Genette used to describe his idea are not so important, yet a general conception of metonymical movements can be seen here:

... all these varieties of didactic summary, or of the summary properly speaking, have in common certain formal features, all of which are pragmatic features: that is to say, the marks of the attitude that underlies the utterance. These features may all be subsumed under two main ones: narration in the present tense, even when the work being summarized as written in the past tense; and narration "in the third person" (heterodiegetic), even when the work being summarized was autodiegetic - not "I became a writer", but "Marcel becomes a writer". (1997: 240)

The key terms that can be taken suitable for metonymical movements within a mental space of contiguity are here "common formal features", "pragmatic features" because of "attitude that underlies the utterance". These three terms are in a first instance appropriate to the concept of metonymy because they describe what might go on making a metonymical movement to express another (alternative) perspective: this procedure depends on the attitude of a speaker/writer ("attitude that underlies the utterance"), is driven by pragmatic reasons, and finally all kinds of metonymical movement follow the same (or similar) "formal" aspects, like replacement of one term by another, e.g., in the sense of hyperonyms, or replacement of tense forms and persons as it was told here in Genette's quote.

Although Genette did not use the term contiguity, reading some of his outlines allows some conclusions toward the concept of contiguity. So we read:

Imitation is thus not a homogeneous class of figures: it displays on the same level imitations of turns from one language to another, from one state of (the same) language to another, from one author to another ... . (1997: 75)

And Genette explains a little bit more precisely what I call contiguity, but on a more abstract, a more metalinguistic level:

Despite Fontanier's attempt to find a place for it in his system of figures, somewhere between inversion and enallage, imitation includes in fact all the figures produced within a state of language or style and imitating another state of language or style. It is distinguished from other figures not, as these are distinguished among themselves, by its formal procedure but simply by its function, which consists of imitating, in one way or another, a language or a style. (1997: 75)

The criterion, which constitutes this metalinguistic concept of contiguity is the equality or similarity of functions of linguistic means. The metonymical movement within a mental space of contiguity can be done by using different linguistic means that fulfill the same or a similar function, here in creating imitations. 
But there is more to perspectivation. The phenomenon of metonymy (or conceptual movements within a mental space of contiguity) can be interpreted several times from Palimpsests. A first idea is described by using the term enallage.

Enallage consists of "an exchange of a tense, a number or a person for another tense, etc." (1997: 74)

This substitution on morphological level is illustrated by Genette using some examples from literature and their translations. For my comprehension of metonymical movements (cf. Drößiger 2015: 205-6), this idea will be a constructive new part of that systemized overview.

Genette describes the relation between "story" and "diegesis" as a metonymical one:

The obvious metonymic relation between story and diegesis (the story takes place within the diegesis) facilitates the shift in meaning, deliberate or not; moreover, there is an easy derivation from diegesis to diegetic, an adjective that has sometimes come to mean "relating to the story" (which historical could not have done unambiguously). (1997: 295)

Interestingly, here we can see that Genette talks about "shift in meaning", which is what I call metonymical movement. Additionally, he states that this can happen consciously or unconsciously. The latter might be an evidence for a deeply innate cognitive and linguistic capability of humans to see the world and how to talk about it. And indeed, it seems like no special efforts must be done to practice or perform that kind of "shift in meaning".

The number of variants or facets related to metonymy in literary research seems to be larger than only by looking at linguistics or cognitive linguistic approaches. Genette impressively demonstrated this by introducing the term "transmotivation". From my point of view, this might be a form of that what I have called evaluative metonymical movement (cf. Drößiger 2015: 141-143, 183184). Genette said:

Transmotivation properly speaking is slightly more demanding, since it requires that the original motivation be displaced by a newly invented positive one ... But the difference is a slight one: given the principle of semantic pressure (culture hates a vacuum), dislodging one motive almost always suffices to conjure up another. Not just any other, for the list is in fact limited ... . (1997: 330)

A change or transport of motivation is, so to speak, nothing else than an evaluative movement within a mental space of contiguity. Genette stated that "the list is in fact limited" can be taken as evidence for that supposed mental space of contiguity. In other words, Genette said that it "is all a question of lighting" ${ }^{3}$

\footnotetext{
${ }^{3}$ A similar idea was described in Lakoff and Johnson talking about "highlighting" and "hiding" in the case of metaphorical conceptualization (2003: 10-3).
} 
commenting the story of Judith who by the work of a writer will be turned from "Judith the Whore" to "Judith the Saint" (1997: 331). Evaluative movements in literature are described by Genette using the term "system of values":

... but it does exist: both protagonists are right, or, if you will, both are wrong in their respective positions as defined by their particular systems of values. (1997: 334)

Mentioning the terms "right" and "wrong" leads within our observation of evaluative metonymical movements to a connection between the evaluative metonymical movements and moral instances. This opens up a new perspective for a theory of metonymical movements in general and in details.

Another facet of metonymical movements in narration is explained by Genette by looking at a whole work (here: the works of Homer) and its potential parts to be "highlighted" by another author:

Lemaitre's "margins" are not the margins so much as the blanks in the epic [the Iliad], where the poet's silence ... leaves room for some addition or variant. One trick consists of foregrounding a secondary character ... Those promotions of sidekicks, which subject the epic diegesis to a slanted or inverted focalization, foreshadow the strategy of Giraudoux's Elpénor. (1997: 335-6)

In a similar way (as in the procedure of Elpenor), Genette presents a palimpsestic technique, which improves or corrects or changes the perspective to the characteristics of the main characters in a literary work. Following my own ideas this is also a variant of metonymical movements:

The "modern" reconstruction of an epic figure will thus consist of complexifying a character that the epic had constructed all of a piece, by "disclosing" beneath each of them ... an ingenuous Ulysses, a cruel Hector, a sentimental Achilles. In actual fact, and by virtue of a "natural" ideological bent, the women are here the favorite targets of such a treatment; their "feminine" ambiguity serves as a counterpoint to the simplicity of the heroes .... (1997: 336)

In an endnote only (1997: 466, endnote 7 to chapter 68), Genette wrote: "... such psychological transpositions have been floating around the Zeitgeist of all ages, and have taken on the status of canonical variations".

And a last point must be mentioned. Genette summarized under the major term transvaluation in a broader sense two single procedures, revaluation and devaluation:

Just as transmotivation, in the broad sense of the word, can be analyzed in terms of motivation, demotivation, transmotivation, so axiological transformation can be broken down into a positive term (revaluation), a negative term (devaluation), and the complex notion of transvaluation in the strong sense of the term. (1997: 343)

Especially about revaluation Genette said:

The revaluation of a character consists in investing him or her-by way of pragmatic or psychological transformation-with a more significant and/or more 
"attractive" role in the value system of the hypertext than was the case in the hypotext. ... Thus, in these instances, revaluation consists not in increasing the importance of the hero but in improving his axiological status through a nobler behavior, nobler motives, or nobler symbolic connotations. (1997: 343-344)

Remarkably, Genette intertwined the evaluative metonymical movement (positive - negative) with categories of reception by audiences ("more congenial") and/or with moral categories (behavior, motivation of a main character). The first refers to an aspect standing outside the literary work (the narration), but this makes the picture of metonymical movements in narration still more complex. The latter is in relation to the intended (by the writer) moral status of a work's character and/or to the interpretation of this character by an audience.

\section{Subject to Palimpsestic Transdoing}

The most prominent subject to any form of palimpsestic transdoing is that what we may call diegesis, the fictitious world wherein a story is told, whereby it does not matter what medium is carrying this story told:

The story told by a narrative or represented by a play is a concatenation, or sometimes more primitively a succession, of events and/or actions; the diegesis, in the meaning suggested by the inventor of the term (Etienne Souriau, if I am not mistaken), which is the meaning I shall be using here, is the world wherein that story occurs. (1997: 295)

In almost the same way Pérez-González used the term (cf. 2014: 308). This was possible because a world, in which a story is told, may have a certain form to give the diegesis a linguistic, but not exclusively, expression of that fictional material, like poems, novels, plays, films, TV shows, opera, musical.

Undoubtedly, one of these forms to give a diegesis a form of expression is text, which plays an essential role in any scholarly studies or branches of scholarly studies dealing with linguistic material. The problem is that a number of notions, descriptions and definitions of text exist, which are not always compatible to one another. Considering this, Genette presented his own understanding of "text" and "text in the second degree" corresponding to his basic idea of hypotext and hypertext and ways to transform a text.

To view things differently, let us posit the general notion of a text in the second degree ..., i.e., a text derived from other preexistent text. ... It may yet be of another kind such as text B not speaking of text $\mathrm{A}$ at all but being unable to exist, as such, without $\mathrm{A}$, from which it originates through a process I shall provisionally call transformation, and which is consequently evokes more or less perceptibly without necessarily speaking of it or citing it. (1997: 5)

This widely applicable conception of text allows to include all complex linguistic constructions that may tell a good story, e.g., from Homers Iliad to the 
newest cinema productions, from an ancient stage play by Sophocles to a film musical like La-La Land.

Amongst several communicative and cognitive specifications any text can contain or can be constructed of, humor takes an especially prominent position, since humor is one of the most complex and most complicated concepts in terms of cognition and communication humans can have, use, linguistically express and produce, and understand. On the other hand, researching humor is a real challenge for any scientist, scholar or researcher, philosophers, psychologists, linguists, translation researchers, researchers in literature etc. Referring to a novel by Thomas Mann, Genette pointed out:

... as Thomas Mann had already said concerning The Magic Mountain, "humor requires space". It requires text, a lot of text, to prepare and express itself (this type of humor, al least). (1997: 268)

This means that for its production and comprehension real humor requires more than only a few funny words. Real humor seems to be a special literary technique or even more: a cultural phenomenon, deeply embedded in humans. On another position, Genette said about humor:

The hypertext at its best is an indeterminate compound, unpredictable in its specifics, of seriousness and playfulness (lucidity and ludicity), of intellectual achievement and entertainment. This ... is called humor, as I have already pointed out, but the term should not be used indiscriminately; it inevitably kills what it pins down. Official humor is a contradiction in terms. (1997: 400)

To sum up we might state that humor is the capability to detect and to comprehend that the text we read (the film we watch) is an instance of hypertext, derived, created, imitated, ... from a hypotext, from an original. Thus, the audience can understand this relation between the hypertext and its preexisting original to get amusement in realizing this relation. This is humor, indeed, because this realization amuses us, evokes fun, satisfaction, and the consciousness to "know".

Other more specified subjects to palimpsestic transdoing can be found in Genette's work, but these are mentioned in almost all cases as illustrative instances without such an in-depth approach like to humor.

\section{Methods/Techniques to Execute a Palimpsestic Transdoing}

In this section, I would like to refer to single methods/techniques of how a transdoing from a hypotext to a hypertext can be done by discussing them based on Genette's outlines on them. Although Genette did not put much effort into outlining translation problems, he described, partially extremely thoroughly, methods/techniques, to which researchers in translation studies are familiar with, yet - as far as I can say - unfortunately, none of these researchers or scholars paid any attention to Genette's work first published in 1982. 
To present these methods/techniques a systematic overview will be given. The basis for this overview is a system of levels/layers, which starts with a most common, strategic level and ends up with a linguistic level directed to certain operations using linguistic means. All in all, four levels of this systemization will be distinguished, and they all represent instances of quality.

On the first level, we may call it the basic level, strategic decisions are to make, which include at least to decide whether a transformation or an imitation has to be executed to attain reasonable quality of the hypertext. Genette himself described the relation between transformation and imitation as follows:

Imitation $\ldots$ is no doubt a transformation, but one that involves a more complex process: it requires, to put it in roughshod manner, a previously constituted model of generic competence .... . (1997: 6)

And finally, I adopt the general term transformation to subsume the first two genres, which differ primarily in the degree of distortion inflicted upon the hypotext, and the term imitation to subsume the two last genres, which differ only in their function and the degree of their stylistic aggravation. (1997: 25)

Genette created a table (1997: 25), in which he categorized transformation and imitation as ways of transdoing a hypotext into a hypertext, which are realized in certain genres considering a major or basic function of each one. This table looks like this:

\begin{tabular}{|l|l|l|l|l|}
\hline Relation & \multicolumn{2}{|l|}{ Transformation } & \multicolumn{2}{l|}{ Imitation } \\
\hline Genres & PARODY & TRAVESTY & CARICATURE & PASTICHE \\
\hline
\end{tabular}

By mentioning that imitation genres differ "in their function and the degree of stylistic aggravation" (1997: 25), Genette leads us to a functional and linguistic level of performing the transdoing because he said that all instances of hypertexts are some sort of imitation by presenting certain kinds of it:

Let us begin with what is clear and actually self-evident: the pastiche is an imitation in playful mode whose primary function is pure entertainment; caricature is an imitation in satiric mode whose primary function is derision; forgery is an imitation in a serious mode whose dominant function is the pursuit or the extension of a preexisting literary achievement. (1997: 85)

The interesting fact herein is that the distinguishing categories are functions, like "entertainment", "derision" and "pursuit or extension". Later on (1997: 87), Genette pointed out that "therefore imitation does function in the three modes: playful, satirical, and serious".

Imitation, according to Pierre Fontanier, is a figure that "consists of imitating a turn phrase, a sentence construction, from another language; or a turn of phrase, a sentence construction, that is no longer in use". (1997: 73) 
All in all, talking about imitation means to focus on linguistic means, which can be used to create such an imitation. This puts imitation close to matters of stylistics, as we can see later in this systematic overview, especially about "figures of construction through revolution".

The strategic decision to execute a transformation or imitation is accompanied with a decision of appropriateness, in what relation of appropriate to the things and appropriate to the addressee (Germ. sachgerecht, adressatengerecht) the transformed or imitated hypertext shall appear. This pair of terms I have introduced and defined in 2011, but only in 2013, I coined the English versions of these terms (cf. Drößiger 2013: 965) with references to a new school of scientific research projects that was called Transferwissenschaft, including all forms, kinds and ways how to transfer knowledge by different means into another sphere, language, culture etc. In this sense of appropriateness, any translation should be done, and doing so, terms like "source language/text/culture" and "target language/text/culture" will become superfluous, sometimes, and may be replaced by the all-purpose-like terms used and defined by Genette, hypotext and hypertext. This can be done quite successfully because a scientific definition of translation can or should focus on the content of the material to be translated, on the audience(s) the translation will be done for and on the particular bundle of methods/techniques to perform any kind of translation. Another fact here is that translations happen also within one linguaculture, as intracultural transpositions, e.g., audio description for the blind, subtitles for the Deaf and Hard of Hearing $(\mathrm{SDH})$, to name a few within the framework of audiovisual translation. Genette mentions the idea of appropriateness as directly related to translation:

La Motte differentiates between two kinds of translations. Translations properly speaking are literal ... Other kinds are "bolder" and "occupy a middle position between simple, literal translation and paraphrase"; those should rather be termed "elegant imitations". In addition to being useful (by giving readers as truthful an idea of the original as possible), they aim to be pleasurable ... Imitation does not quite seem to be the fitting notion here, since the original is taken not as a model but as an imperfect object to be improved according to a model of perfection not its own but that of the perfecter and his audience: the Iliad might well have been faultless for the taste and morals of its age, but our morals and our taste are different, and they must guide an elegant translator in his work. (1997: 312-3)

One appropriateness is the one to the object, as we can read it in Genette's "useful"; the other appropriateness is that to the addressee, as Genette puts it as "the model of the audience". Both the translator, here called "the perfecter", and the audience must have in mind to be aware of a translation. In other words, we might call this double feature of being guided by these appropriatenesses a strategic decision for conducting any form of translation, respectively.

Yet, we might go further by saying that translation itself is the strategy because the aim and the purpose of a translation is to provide media content to another audience than this media content was originally produced for [for a thorough description see Snell-Hornby (2006)]. This basic insight may prevent us 
from an inflationary use of "strategy" to name methods and techniques that are really practiced doing a translation.

The second level within this systematic overview we may call the diegetic level. This corresponds to the instance of diegesis. Since the goal of any transdoing is to create a reasonable, fairly generated hypertext on the basis of a given hypotext, the content of both of them plays a major role. Considering the comprehension of the term diegesis, all parts and forms of the story told in a fictitious world we call diegetic world may undergo modifications, changes and the like. The essential point herein is that these parts and forms appear as semiotic components, which can be subsumed as the multisemiotic or polysemiotic character of the hypotext-hypertext interrelation. Thus, methods/techniques to modify, change, alter a hypotext by transdoing it into a hypertext affect the diegetic world. Genette has mentioned only a few of such methods/techniques, which may give good reason to research into more of these methods/techniques. The fact that this level is also strictly quality related can be noticed in what Genette called diegetic faithfulness. Within the framework of all possible transformations, he gave some outlines about diegetic transpositions, amongst these he talked about diegetic faithfulness:

An almost infallible sign of diegetic faithfulness is the preservation of the characters' names, which is a sign of their identity - i.e., of their inscription within a diegetic world: a nationality, a gender, a family background, etc. ... . (1997: 297)

This faithfulness plays from my point of view an essential role in translations, especially in film translation. If we additionally take such characteristics of fictitious individuals like linguistic behavior (the way how to speak), sociolinguistically determined features like lect, accent, style, register, paraverbal and nonverbal forms of individuals' appearances, then the diegetic faithfulness might become a major factor determining a strategic translation decision and its subsequent translation methods/techniques. It is a matter of fact that other semiotic characteristics than language use and linguistic behavior within a diegetic world complete the tasks to process a transdoing, especially a translation of audiovisual content.

As one of a possible subsequent instance to this faithfulness, Genette described a linguistic and a cognitive means as well, calling it diegetic metaphor:

... a "good" metaphor is one imposed by the context and the situation, be it a diegetic metaphor or a metonymic one. Don't say, of the bell tower at Combray, that it appears to be covered with shells. The sea is too far away; we are in Beauce. Say, therefore, that it resembles an ear of grain. (1997: 109)

Interestingly, this description of a "good" metaphor leads not so strictly to the real metaphor in the sense of cognitive linguistics. If Genette really has some sort of logical relation between an object (the bell tower) and its environment (the situation) and the (linguistic) context in mind, then we might talk of a mental space of contiguity. The consequence is that we need to prefer the term metonymy instead of metaphor. If, in a next, more metatheoretical instance, context and 
situation determine a "good metaphor" (i.e. a metonymy in the sense that linguistic signs (words) represent the object they are designating), then we really might take this relation as a metonymical one between the signifier and the signified.

Further on, Genette explicitly makes some remarks about a diegetic expansion:

The diegetic expansion by itself is wedded to the extradiegetic "intrusions" of a verbose narrator, very much imbued with his didactic function and very ostensibly omniscient. (1997: 266)

In a first instance it seems to be not very likely applicable to translation studies. However, the key word appearing in this quote is "extradiegetic" since it names a number of methods/techniques to be used to tell what is (necessary) to get a full understanding of the hypertext but standing somewhat outside of it. In the case of SDH, we might also state such "intrusions" as sound information is verbalized on the screen (noises, kind of music, ways to utter, paraverbal signals) by expanding subtitles.

Talking about a transfer from poetry to prose (and possibly vice versa) but interchangeably between literary genres, Genette focusses on some aspects of a dramatization in several ways, from prose (and possibly poetry) to dramatized text sorts like theatre play, and last but not least to films, not simply by creating a new kind of only written material but now to bring a plot to the stage or to produce a filmic adaptation.

The dramatization of a narrative text, which generally goes with an amplification ..., is to be found at the fountainhead of our theater: i.e., in Greek tragedy, which almost systematically borrows its subjects from the mythic-epic tradition. This practice has persisted along the course of history, with the medieval Mystery Plays (based on the Bible) and Miracle Plays (based on the lives of the saints), the Elizabethan theater, neoclassical tragedy, down to the modern device of dramatic "adaptation" (mostly filmic nowadays) of popular novels ... . (1997: 278)

To put this into a short formula, we might state that dramatization is a way of changing the quality of the diegetic world by practicing a kind of amplification plus a perspectivation due to the interests of an audience, the requirements of a genre, and the functions of the created hypertext within a community.

The third level of this systematic overview shall be named the textual level. It basically includes the seven textual parameters as we know them from text linguistics. However, having Genette's conception of text in mind as one of the subjects to any kind of transdoing, there is more to text than these classical seven aspects of textuality. To some extent, the instances Genette discussed, correspond to the diegesis as described here as the second level. The reason for distinguishing this third level from the second is the fact that other semiotic components than language use and linguistic behavior do not play any role here. A text, in what form it ever might appear, might be subject to transdoing in the following ways Genette has described.

Amongst a number of methods/techniques operating on textual level to change or to modify a text, Genette talked about several ways to perform a text 
transformation. A first way subsumes several instances of extension, none of them is called augmentation:

Just as the reduction of a text cannot be a simple miniaturization, so its augmentation cannot be a simple enlargement; as one cannot reduce without cutting, one cannot augment without adding, and both operations involve significant distortions. (1997: 254)

Going into more details, Genette not only put the augmentation into opposite to that what he named "miniaturization", but he also gave more explanation to this term:

Thematic extension and stylistic expansion should therefore be considered as the two primary paths of augmentation in general, which most often consists in their synthesis and convergence and for which I reserved the classical term amplification. (1997: 262)

The fact that Genette describes amplification as a combined procedure that brings more to the original text than it was given, can be a good reason for some interpretation towards translation or some techniques presenting a translated text. Typically, within the framework of Audiovisual Translation Studies (AVTS), the presentational technique named audio description is similar to that "extension" plus "expansion" - an amplification. Later on, Genette described a specialized form of amplification by calling it narrative amplification:

That amplification proceeds chiefly through diegetic development (that is the role of expansion: distension of details, descriptions, multiplication of episodes and secondary characters, maximum dramatization of an adventure hardly dramatic in itself), through metadiegetic insertions (that is the main role ascribed to extension: episodes that are extraneous to the initial theme ...), and through the narrator's extradiegetic interventions .... (1997: 264-265)

This narrative amplification seems to be more or less corresponding to audio description because of including metadiegetic and extra-diegetic aspects.

On the opposite to all possible ways of extending a text, Genette named an described a number of reduction methods/techniques. For a special interest of translation some methods/techniques to shorten a text, by reduction, elimination or by some other procedures can be told.

One cannot reduce a text without diminishing it or, more precisely, without subtracting from it some part or parts. The simplest, but also the most brutal and the most destructive to its structure and meaning, consists then of suppression pure and simple, or excision, with no other form of intervention. (1997: 229)

In any case, reduction by amputation (a single massive excision) is a very widespread literary, or at least editorial, practice. ... And there is no doubt, here and so often elsewhere, that this practice of rewriting is built upon (and in its turn reinforces) a practice of reading, in the strong sense: i.e., a choice of attention. (1997: 229-230) 
Here I clearly see potential for the practice of editors of audiovisual translations (in a bad sense) because the reduction of a text only to make it fit on behalf of, for example, tech specs of subtitles seems to be too weak as an argument for text shortening. If we take this process of shortening from its psychological and ideological perspectives, the editors hold in their hands a mighty instrument of manipulation. It is not only to direct thinking or to turn the attention while reading, it is an instrument to heavily infringe upon the original quality of a film (or any other material to be translated). Thus, the general question arises what would be the real reasons for shortening the translated text of a film dialogue to create subtitles? And, is such a shortening really necessary?

Later on, Genette very briefly discusses methods/techniques of trimming or pruning, and self-excision (cf. 1997: 230-1):

Self-excision (I mean the amputation or pruning of a text not, of course, by itselfthough that would be the ideal - but, failing that by its own author) is obviously a special case of excision. (1997: 231)

Condensation as one of the techniques to reduce a text, is described in Genette's Palimpsests according to text sorts, which can be taken as what Genette calls paratexts:

The reduction, here, operates by condensation; its product is commonly called digest, abridgment, résumé, summary, or, more recently in French high school parlance, text contraction. (1997: 238)

A last method/technique to be mentioned here in this overview is concision:

A distinction must be made between excision ... and concision, whereby a text is abridged without the suppression of any of its significant thematic parts, but is rewritten in a more concise style, thus producing a new text which might, at a pinch, preserve not one word of the original text. (1997: 235)

The fourth and last level shall be named the linguistic level because Genette includes methods/techniques to it, which can be sorted as syntactical, lexical or other means directly related to a methodological understanding of language as a construct of components or layers.

A first example in Genette's work is a syntactical one but with an impact on the style of a text. Turning to stylistics, we can find this category, the stylistic figure of permutation, one of the basic stylistic means in a language. In Genette's Palimpsests, talking about palimpsestic transdoing, this category gets some different characteristics:

... a turn is a construction: i.e., a way of arranging words in a sentence. This is in principle what is imitated in the figure called imitation - that, and nothing more.

In Fontanier, imitation belongs with "figures of construction through revolution". Figures of construction are unlike other types of figures in that they affect only "the assemblage and arrangement of words in speech". 
Now there are only three ways of affecting the order of words in a sentence ... One consists either of suppressing certain words, whence the figures of construction obtained by "implication", such as the ellipsis or the zeugma; or of adding other words, whence figures of construction through "exuberance", such as the apposition or the pleonasm; or of modifying the word order itself by placing first what should be last and vice versa, whence figures of construction through "revolution": namely, inversion or hyperbaton ... Enallage ... . (1997: 74)

If we take this explanation literally or intralinguistically, there are no serious problems to be detected because variation in style is in all languages a common procedure to create texts of high quality in style and register. However, looking at translation processes, the problem appears in a different way, on a more abstract level of observation and description: How may the translated version of a text created by using means of stylistic permutation, like mentioned in Genette's outlines, as ellipsis, zeugma, apposition, pleonasm, inversion, hyperbaton, enallage, be characterized by these stylistic means?

A second group of single methods/techniques that are in use to generate a hypertext are lexical ones. From the numerous categories of the vocabulary of a language, Genette considered only the following two: Very seldom Genette focused on single linguistic categories like parts of vocabulary, semantics of certain words, morphological forms, or syntactic constructions. However, there is one good example to talk about certain categories of the vocabulary of a language, as not only Genette did: xenism.

Xenism or xenotism (from xenos, "stranger") is a little too restricted to the field of relationships between languages; it could serve to designate all the translinguistic replications (Anglicisms, Gallicisms, etc.), but it is not suited for other types of imitation; exotism would replace it rather advantageously, come to think of it ... . (1997: 80)

And about what seems to be so popular amongst numerous scholars of translation studies, Genette had only one short statement to give: "For imitation is not borrowing ... (1997: 77)". In his work, the category of borrowing is illustrated by some English-French examples. Apparently, it is not enough about borrowing compared to many other works on semantics, etymology or lexicology.

\section{Conclusion}

Returning to the promise given in the subtitle of this article, ways are to be proposed how to apply the concept of palimpsest to translation studies. The term translation studies shall be taken as a general one that may fit all forms, directions, and schools of translation studies. This is possible because the application of Genette's notion of palimpsest grounds on basic components for any form or kind of translation studies (Figure 1). 
Figure 1. The Complete Conception of Palimpsests according to Genette

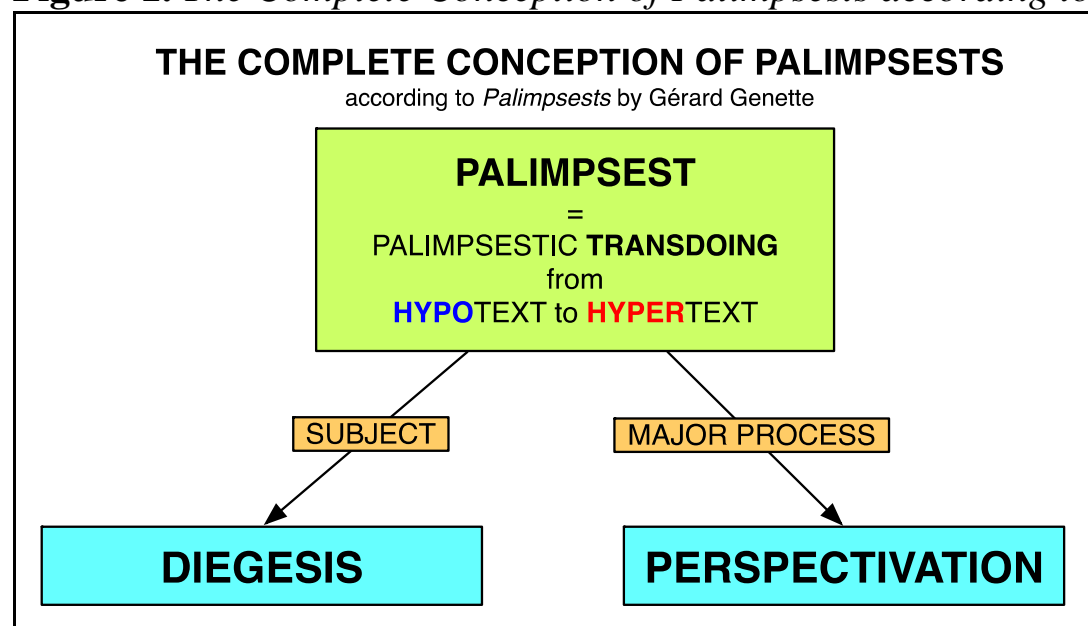

Source: Author's calculations.

Figure 2. Levels of Transdoing. An Interpretation to Palimpsests by Genette

\section{LEVELS OF TRANSDOING}

\section{STRATEGIC LEVEL}

\section{DIEGETIC LEVEL}

\section{TEXTUAL LEVEL}

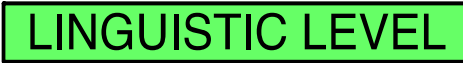

DECISION to TRANSDOING: MEDIA, CULTURE, SOCIETY

SEMIOTIC COMPONENTS

COMMUNICATIVE FUNCTIONS

Source: Author's calculations.

First, since translation is understood as a special form of transdoing, which might be performed as a change from an instance that might be named $\mathrm{A}$ into an instance that could be named $\mathrm{B}$, and because of the fact that the result of a translation depends on the needs, wishes or other expectations of a certain audience, translation can be described as a simultaneously conducted taking over of linguistic, textual, semiotic, medial, cultural, and social content.

Second, the previously named instances A and B are connected in a unidirectional way, whereas B is derived from A not only by content but, more importantly, in terms of chronology as the newer, younger one. Genette's terms taken from Greek roots exactly name this special kind of relation, in which A is the hypotext and $\mathrm{B}$ is the hypertext. This distinction allows to cover all subjects to translation under the condition that text must not be seen as a pure linguistic 
phenomenon but as a complex presentation of content. Additionally, the distinction between hypotext and hypertext allows to avoid confined terms like source text, source language, source culture, target text, target language, target culture, if translation is understood as a process that includes linguistic means, textual functions, communicative intentions and semiotic components as well as aspects of media, culture and society.

Third, if hypotext and hypertext are taken as fundamental categories involved into translation, then its subject and major process are to be told. As subject of translation appear diegesis containing all verbal, non-verbal, paraverbal, communicative, cognitive, and semiotic parameters a diegetic world is constructed of. As the major process of translation, perspectivation shall be taken.

Fourth, the execution of any translation is a process consisting of at least four levels of sub-processes, the linguistic, textual, semiotic, and diegetic level. These levels correspond to the main characteristics of a hypotext that shall be translated to get a hypertext (Figure 2).

Considering the fact that Genette only particularly outlined problems of translation, it will be up to scholars working in the field of translation studies to seek out a more complete picture of that what translation studies might be. All the given abstractions, conclusions, terms and their descriptions in these "Conclusions" are suggestions to continue the scholarly discourse about translation studies in general and in audiovisual translation studies (AVTS) as well. However, the theoretical and methodological foundations of especially AVTS are still unsatisfying. The reason for this seems to be not only the irritating diversity of terms that are too often used inconsistently, which makes a flawless scholarly discourse quite difficult, but also the unsolved problem where the place of AVTS amongst scholarly areas shall be. Looking to the components of the designation of this branch of scholarly research work in theory and practice, two places are possible: 1) AVTS might belong to the field of research into audiovisual communication. The reason for this is slightly clear since any audiovisual production communicates audiovisual content and may be taken as a form of presenting a diegetic world. 2) AVTS might belong to translation studies as a branch in its own rights. Yet, this would require a stable and reliable terminology and a unique and coherent understanding and use of research methods.

\section{References}

Antos G, Wichter S (Eds.) (2005) Wissenstransfer durch Sprache als gesellschaftliches Problem [Transfer of Knowledge by Language as a Societal Problem]. Frankfurt/ Main: Lang.

Barthes R (2000). Introduction to the Structural Analysis of Narratives. In Sontag S (Eds. and intro.), A Barthes Reader (pp. 251-295). London: Vintage/Random House. [Original: 1966]

Díaz Cintas J (2004) In Search of a Theoretical Framework for the Study of Audiovisual Translation. In Orero P (Eds.), Topics in Audiovisual Translation (pp. 21-34). Amsterdam, Philadelphia: Benjamins. 
Drößiger H-H (2013) On Culture-Bound Words in the Brothers' Grimm Fairy Tales and Their Equivalents in English Translations. Sociology Study 3(12): 962-973.

Drößiger H-H (2015) Realienbezeichnungen in den Kinder- und Hausmärchen der Brüder Grimm. Intrakulturelle und interkulturelle Aspekte [Culture-Bound Words in the Brothers Grimm Fairy Tales. Intracultural and Intercultural Aspects]. Hamburg: Dr. Kovač.

Fernández MJF (2009) The Translation of Swearing in the Dubbing of the Film South Park into Spanish. In Díaz Cintas J (Eds.), New Trends in Audiovisual Translation. Bristol, Buffalo, Toronto: Multilingual Matters.

Genette G (1997) Palimpsests. Literature in the Second Degree. Translated by Channa Newman and Claude Doubinsky. London: University of Nebraska Press.

Graumann CF, Kallmeyer W (2002) Perspective and Perspectivation in Discourse. An Introduction. In Graumann CF, Kallmeyer W (Eds.), Perspective and Perspectivation in Discourse (pp. 1-11). Amsterdam: Benjamins.

Holmes JS (1988) The Name and Nature of Translation Studies. In Holmes JS (Eds.), Translated!: Papers on Literary Translation and Translation Studies (pp. 66-80). Amsterda: Rodopi. [Originally published in 1975].

Lakoff, G. and Johnson, M. 2003. Metaphors We Live By. The University of Chicago Press, Chicago. London.

Molina L, Albir AH (2002) Translation Techniques Revisited. A Dynamic and Functionalist Approach. Journal des Traducteurs/Translators' Journal 47(4): 498512.

Pérez-González L (2014) Audiovisual Translation. Theories, Methods and Issues. London, New York: Routledge.

Snell-Hornby M (2006) The Turn of Translation Studies. New Paradigms or Shifting Viewpoints? Amsterdam, Philadelphia: Benjamins.

Wichter S, Antos G (Edn.) (2001) Wissenstransfer zwischen Experten und Laien. Umriss einer Transferwissenschaft [Transfer of Knowledge between Experts and Laymen. Outlines of a Science of Knowledge Transfer]. Frankfurt, Main: Lang. 
